\title{
A Tale of Two Pedagogical Perspectives: A Literature Review of Writing Program Administration Within Engineering Programs
}

\author{
Laura M. Patterson \\ University of British Columbia \\ laura.patterson@ubc.ca
}

\begin{abstract}
While communication and writing programs are typically housed in humanities-focused departments, engineering programs often employ full-time writing specialists to teach their students effective communication in engineering-specific contexts. However, bringing together humanities-focused writing instruction within a science-focused engineering program has some inherent complications in administering a program within a program.
\end{abstract}

The challenge of these writing programs is the misunderstanding that can arise between communication faculty and engineering faculty and administration. The opportunities and challenges embedded within communication and writing pedagogy is not always understood by the engineering-educated administrators, nor sold particularly well by the communication faculty. These challenges are made evident when we see that the modern conversation around engineering communication has morphed from convincing a composition audience to broaden their conception of writing for the unique writing needs of their engineering students, to a post-outcomes based world where engineering identity and culture are the center of curricular discussions aimed at fellow engineering educators.

While the complete history of writing program administration in engineering education is much longer, this literature review explores key works in the last 25 years to demonstrate themes in current curricular programming challenges in administering writing and communication programs within engineering departments in Canada and the United States.

Keywords: Writing program administration, writing in the disciplines, writing across the curriculum, engineering communication, technical communication, accreditation

\section{INTRODUCTION}

While communication and writing programs are typically housed in the humanities, engineering programs often employ full-time writing specialists to teach their students the skills necessary to be effective communicators in an engineering context. This need for specialized communication and writing instruction in engineering education is also emphasized directly in one CEAB graduate attribute (communication skills) and underpins several others (individual and team work, professionalism, ethics and equity, and lifelong learning).

These writing programs are offered with in engineering in a variety of ways: formal programs within larger engineering departments, informal groups of faculty designated to teach engineering communication courses, in-house faculty teaching writing integrated into existing engineering curriculum, and many other variations. Regardless of the administrative structuring, administering these specialized writing programs within engineering departments is more common than ever before.

Over the past 25 years there has been a shift in audiences for literature on engineering writing program administration (WPA) - literature on the organization of all elements of writing instruction to engineering students including, but not limited to, course offerings, assessments, teaching assistant training, extracurricular workshops, cross-disciplinary collaborations etc. The challenge has been some engineering faculty and administration do not always understand what goes into teaching communication so students will be able write effectively as professional engineers, as Patton asserts, "The default expectation that there is some course, some fix for writing, may trace in part to a mechanical view of writing as a set of proofreading skills, to simple wishful thinking, or perhaps to not thinking at all" [19]. However, it is unreasonable to expect those educated in engineering to understand the need for comprehensive nature of WPA without clear explanations from their communication specialists. Attempting to bridge this gap might account for why the literature in WPA in engineering education has shifted from composition instructors to engineering education administrators.

However, as the audience has shifted, the literature on WPA in engineering education has been diffusely distributed across several journals and only concentrated in rare special issues dedicated to the topic, or niche 
subgroups within engineering education conferences. This literature review chronologically explores some key works in the last 25 year to collect key themes in curricular programming challenges in engineering communication from these diverse areas to continue to bring the disciplines together.

\section{1990s: DIFERENTIATING ENGINEERING COMMUNICATION NEEDS}

Though the roots of engineering communication began in the industrial revolution and took shape as the need for consistent and systematic communication strategies grew with the immense scale of building rail systems across North America [10], the pedagogical issues we see today trace back to Winsor's discussions of engineering communication directed to a composition audience to help them understand the value of the different kinds of technical communication that happen in engineering settings and see them as technical writing [24, 25, 26]. Winsor defines engineers for composition scholars to help demonstrate the difference in thought processes: "Engineering defines itself as a field concerned with the production of useful objects. In keeping with this concern, engineers tend not only to see their own knowledge as coming directly from this physical reality without textual mediation, but also to devalue the texts engineers themselves produce, seeing them as simple write-ups of information found elsewhere" [24]. As a result, she states, "writing is viewed as a part of an engineer's job but not as part of engineering, which presumably happens in some separate, prior realm" [24]. She concludes "They inscribe a written representation of physical reality and then use more writing to build agreed-upon knowledge and their own characters as engineers" noting, "The engineer differs from the rest of us, perhaps, only in showing greater resistance to knowing that language mediates experience" [24]. Winsor is making an important distinction here differentiating an engineer's understanding of language as separate from the epistemological processes of physical design.

This composition and writing audience who teach engineers needed at that time to broaden their conception of writing to appropriately teach engineering students. Winsor [25] addresses this need in her further work by widening the definition of what writing looks like in engineering including graphics, routine forms, and shipping documents. She asserts that these discourses still count as "writing" because they require both human presence and words to understand, even though these means of communication are not formal writing as composition might conceive of it. In this way, rhetoric begins to play a more explicit role in the conceptions of engineering writing.
As the more rhetorical conceptions of engineering writing began to gain ground, Writing Across the Curriculum (WAC) and Writing in the Discipline (WID) strategies were being reported on in the late 1990s. In a special issue of Language and Learning Across the Disciplines (now renamed Across the Disciplines), Olds, Leydens, and Miller [14] present an example of using a WAC model in an engineering setting at the Colorado School of Mines to meet ABET (Accreditation Board of Engineering and Technology) accreditation needs. In the same special edition, Irish [7] discusses strategies WID consultants can use to guide faculty in creating meaningful writing assignments within engineering departments. This WPA in engineering education focused issue brought together Canadian and American scholars and began a shifting the conversation from strictly composition scholars to a cross-disciplinary perspective.

This cross-disciplinary shift continued to engineering education-focused publications shortly after. In a 2000 issue of the Journal of Engineering Education, Walker [22] presents a survey of other engineering writing programs pre-2000, confirming the WAC/WID themes and also her discovery in engineering communication education of "cross-disciplinary team teaching... a strong implementation of real-world workplace communication scenarios... internships that involve writing and have integrated such assignments into existing engineering courses, ... [and] partnerships with a university-wide writing centre or with a writing consultant who interacts specifically with engineering students outside of their courses" [22]. Around that same time, Shwom et al [20] published an American Society for Engineering Education (ASEE) conference paper showing similarities between design processes and writing processes that can be highlighted in these cross disciplinary approaches. Programmatically, these articles seem to mark the beginning of the basic strategies for integrating engineering communication education that continue to this day.

\section{EARLY 2000s: A POST OUTCOME-BASED EVALUATION WORLD}

In the early 2000s, the challenges of integrating humanities-based education in engineering programs become a discussion about resources. ABET had just shifted to outcome-based evaluation, shortly followed by the $\mathrm{CEAB}$, and communication skills were a clear priority for engineering programs to address.

Some of the strategies presented in the literature immediately following the changes were occasionally "quick fixes" with limited resource support, and sometimes dubious in their quality. For example, one study reported on a system to be integrated by technical 
faculty that "allows even instructors without great confidence in their own writing abilities to help students develop better, more effective writing skills and strategies" [3]. While this claim seems questionable, their primary aim for their system was "to teach them how to connect their ideas on paper in a sequential manner without ambiguity" [3]. The effectiveness of their system is questionable as the metrics to determine success are the grades of the students and the average grading time by the instructor, metrics that are potentially subjective with no mention of how they were validated [3]. Despite these issues, Boyd \& Hassett's [3] underlying goal of teaching engineering students to connect their ideas sequentially in their writing is admirable and shared by others [23]. Even if the strategy to achieve it was not the best, studying approaches to quantify teaching coherent writing is a demonstrable priority in engineering education.

A more realistic strategy to addressing engineering communication education effectively proposed at the time instead is to recognize the limitations of undergraduate engineering education in the new accreditation climate and work with in those. Wheeler \& McDonald [23] address the challenges of the nature of undergraduate education and the new outcomes-based graduate attributes: "Four years is an insufficient time for students to achieve a high level of proficiency in all these areas. Rather, undergraduate engineering education should form the basis for a lifetime of learning" adding that educators "must ensure that graduates have the necessary core proficiencies for lifelong learning... [and] provide their students with the tools needed to learn" [23]. In the quest for efficient use of resources while maintaining quality of engineering communication education, arguments begin to shift towards defending more integrated engineering communication within their programs in order to "make room for communication in engineering education" [6]. Focusing on preparing students for their holistic communication needs as future engineers has continued to be a useful framework to address the resource pressures rather than spot fixing specific writing issues.

As the 2000s progressed, a more explicit conversation surrounding WPA administration in engineering education emerged. At the 2007 ASEE conference, Paretti et al [18] connected WPA outcomes with ABET outcomes to demonstrate how the goals of these two seemingly different disciplines were in fact highly interconnected: "The points of intersection are not limited to the mechanics of writing, but instead address broader metacognitive skills necessary to move from one communication situation to another; they also address collaboration, critical and analytical thinking, collaboration, and ethical behavior" [18]. It is here where the literature shifts to discuss where communication specialists can help address broader considerations of engineering education.

\section{2008: IDENTITY, CULTURE, AND RESOURCES}

In 2008, a special issue that focusses on communication in engineering curricula was released by IEEE Transactions on Professional Communication. Paretti and McNair [16] open the issue by acknowledging the time lapse since Language and Learning Across the Disciplines' dedicated issue and by defining the present challenges in engineering communication education. They note that engineering is more about communication across the curriculum and in the discipline than WAC or WID, revisiting Winsor's [25] argument of broadening the conception of what counts as communication in the new reality as technology had developed in the previous ten years. Paretti and McNair [16] also acknowledge the issues of bringing together such disparate specializations as communication and engineering, as well as administrators' challenges of adapting engineering curricula to accommodate "an ever-expanding technical knowledge base" [16], leading to their "struggle to integrate communication assignments, which generally require more time to evaluate, into already jam-packed courses" [16]. The conversation at that moment in time is still about justifying the resources to appropriately teach communication in an engineering curriculum.

One of the core themes arising in the 2008 special issue is identity and culture in the engineer's discourse community. Many of the scholars in this issue assert the importance of teaching communication skills within the engineer's discourse community: "To optimize learning to write like an engineer, we need a broad view of language experiences closely tied to engineering and opportunities to reflect on those language practices" [19]. Leydens [8] concludes his extensive qualitative study of students and professionals perspectives on writing in the engineering workplace by articulating the need for students to practice communicating in situations specific to that community: "To teach rhetoric well in technical contexts is to humanize the making of scientific and engineering knowledge and material artifacts, to work toward an ideal of engineers who can learn to communicate effectively in any activity system, especially in high-stakes situations, and to work toward an ideal of engineers whose curriculum allows them to be and to enact more fully integrated selves" [8]. This task is not easy because research reported on in that same issue shows that identity creation is an iterative process: "Students struggle to develop a professional identity, even within the space of seemingly simple writing activities in the disciplines and, thus, reveals how we must constantly revise and update our approaches to help students gain a professional identity in that discipline" [5]. Rather than focusing on 
teaching communication, engineering educators are now called upon to create situations where students participate in the culture of engineering through their writing practices.

That desire for a full integration of communication into the culture of the engineering student led to faculty in engineering communication working to integrate engineering-related material into the regular writing instruction. Ballentine [1] asserts, "it is our responsibility as instructors to continually update courses essential to student success, such as professional and technical communication" and offers a course which uses "a fourpart thematic structure intended to foster students' relationships to writing" which focusses on themes of "(1) ethics, accountability, and professionalism; (2) intellectual property; (3) design, creativity, and invention; and (4) globalization" [1]. Design courses, particularly capstone design courses, have been explored as viable sites for integration of communication within engineering curricula. Paretti [15] asserts that "the development of communication skills relies heavily on situated learning, in which the context surrounding an assignment can be as important as the assignment itself" [15]. She notes that capstone design courses are a particularly viable site for such situated learning of communication because students must place themselves in a professional role in order to complete their writing and communication assignments. At MIT, they offer what they call a communicationintensive (CI) version of integrated communication instruction within engineering programs which were made up of four CI classes, including two of which are in their majors. Their goal was "to work with engineering and science faculty to design meaningful, well-defined assignments, use revision and peer review to improve student writing, develop learning goals, and effectively assess student writing" yet found they ended up "mov[ing] beyond these initial steps to writing and speaking activities that resemble more the advanced challenges of engineering communication that occur in the practice of doing engineering" [5]. Communication education in engineering was moving towards more comprehensive integration to help professionalize engineering students.

\section{2009-PRESENT: INTEGRATION AND DEPARTMENTAL BUY-IN}

However, even after the discoveries and arguments made in IEEE Transactions on Professional Communication's special issue, the concerns over resource allocation to engineering communication programs within engineering curricula is still a common theme in the literature. In an attempt to understand the role of composition within engineering programs, Leydens and Schneider [9] did a comprehensive study of composition program administrators at six technical institutions about their teaching strategies and how they negotiate the increasing competition for space within engineering curricula. Leydens \& Schneider [9] acknowledge that while focusing on identity and enculturation in engineering communication education requires additional resources that some programs cannot afford, engineering educators work towards "moving from culture vs utility to culture and utility" [9]. Without that shift, collaborations on teaching communication in engineering education "may end up being merely symbolic" [9]. Continuing Leydens \& Schnieder's work is a possible area for further study, to determine how successful these efforts have been both at teaching students better communication skills and their reflections on their professional identities.

More recently, explicit discussions of integrating communication in engineering curricula have continued as parts of larger conversations on transforming engineering education. Chong, Irish, and Foster [4] overview their integration of communication into a larger design course for IEEE's ProComm conference in 2010. The conversation seems to be moving towards understanding engineering faculty perceptions of writing so that communication specialists within the programs can better serve their needs. At the 2012 ASEE conference, Matusovich et al reported on the first phase of a three-year study examining engineering faculty beliefs on communication and teamwork skills [12]. Their work was built upon in a further study presented at the ASEE conference in 2016 which found "While faculty recognize the need and importance of teaching writing in engineering, they face many challenges whey trying to incorporate writing in their courses. Faculty identified time as the largest challenge" [22]. It is important to note that instead of defending writing specialists' existence in an engineering program, the discussion is beginning to shift to how to productively integrate the communication instruction in the face of ever-tightening resource allocations.

Two articles in the Journal of Engineering Education are, or seem to be sold on communication's permanent place within their programs among other accreditation driven changes, but now look to making the necessary shifts in faculty and administrators' attitudes to get the buy in to move forward on these changes $[2,11]$. Because integration of communication and professional identity requires collaboration from both faculty and administration, it is not surprising that analysis of their attitudes and values has been a recent area of study.

\section{ENGINEERING EDUCATION IN WPA LITERATURE}


Only two articles were found within the formal writing program-specific literature directed specifically to writing program administrators that included engineering. One was authored by already cited experts on engineering communication education, Marie Paretti and Lisa McNair [16] who penned the introduction to the special issue on the same topic in IEEE Transactions on Professional Communication the year before. Rather than it focusing on educating engineers, it was more about crossdisciplinary collaborations between writing centres, one of which that was humanities based and the other that was engineering based [16]. The other was about the perspectives of an engineer teaching writing as compared to a literature scholar teaching writing [13]. It seems that the writing program audience is more interested in the generalities of cross- and multi-disciplinary perspectives instead of the specific challenges of engineering communication gaining ground within engineering programs. This is completely understandable as engineering writing program administrators have more work to do in keeping the dialogue going with their fellow engineering colleagues rather than those who already understand the complexities of teaching communication.

\section{CONCLUSION}

The discussion surrounding integrating communication into engineering education over the past 25 years has taken a productive shift from two separate disciplines with seemingly separate goals to a cross-disciplinary collaboration with one shared goal-supporting engineering students as they become practicing engineering professionals. The benefits of communication skills and multidisciplinary perspectives are clearly valued and seen as necessary to the education of an engineer. In particular, the ability for communication instruction to help enculturate engineering students within their discourse community is highly valued.

However, there are still key issues with which writing program administrators (formal or otherwise) in engineering still have to contend. Our shared goals still need to be met in the face of the resource pressures of the rigorous technical curriculum also called for by accreditation requirements. As a result, the current movement in engineering communication education literature seems to be towards understanding how to get faculty and administrative buy in to continue integrating communication into the broader engineering curriculum.

It is important to take this overview of the progress these two disciplines have made over the last 25 years to understand how we can continue to work together in the future to educate engineering professionals, professionals who can make sound technical decisions and communicate those decisions and their implications effectively and ethically.

\section{References}

[1] Brian D. Ballentine, "Professional communication and a 'whole new mind': Engaging with ethics, intellectual property, design, and globalization," IEEE Transactions on Professional Communication, vol. 51, no. 3, pp. 328-340 , September 2008.

[2] Mary Besterfield-Sacre, Monica F. Cox, Maura Barrego, Kacey Beddoes, Jiabin Zhu, "Changing engineering education: Views of U.S. faculty, chairs, and deans," Journal of Engineering Education, vol. 103, no.2, pp. 193 219, April 2014.

[3] Greg Boyd, Marie F. Hassett, "Developing critical writing skills in engineering and technology students," Journal of Engineering Education, vol. 89, no. 4, pp. 409-412, October 2000 .

[4] Alan Chong, Robert Irish, Jason Foster, "Using problem finding to integrate communication and design for student learning in engineering," 2010 IEEE International Professional Communication Conference. July 7-9, 2010. Enschede, Netherlands. 119-120.

[5] Jennifer L.Craig, Neal Lerner, \& Mya Poe, "Innovation across the curriculum: Three case studies in teaching science and engineering communication," IEEE Transactions on Professional Communication, vol. 51, no. 3, pp. 280-301, September 2008.

[6] Julie Dyke Ford, Linda Ann Riley, "Integrating communication and engineering education: A look at curricula, courses, and support systems," Journal of Engineering Education, vol. 92, no. 4, pp. 325-328, October 2003.

[7] Robert Irish "Engineering thinking: Using Benjamin Bloom and William Perry to design assignments," Language and Learning Across the Disciplines, vol. 3, no. 2, pp. 83-102, July 1999.

[8] Jon A. Leydens, "Novice and insider perspectives on academic and workplace writing: Toward a continuum of rhetorical awareness," IEEE Transactions on Professional Communication, vol. 51, no. 3, pp. 242-263, September 2008.

[9] Jon A Leydens, Jen Schneider, "Innovations in composition programs that educate engineers: drivers, opportunities, and challenges," Journal of Engineering Education, vol. 98, no. 3, pp. 255-271, July 2009.

[10] Bernadette Longo, Spurious Coin: A History of Science, Management, and Technical Writing. Albany: State University of New York Press, 2000, 222 pp.

[11] Holly M. Matusovich, Marie C. Paretti, Lisa D. McNair, Cory Hixon, "Faculty motivation: A gateway to 
transforming engineering education," Journal of Engineering Education, vol. 103, no.2, pp. 302-330, April 2014.

[12] Holly M. Matusovich, Marie C. Paretti, Andrea M. Motto, \& Kelly J. Cross, "Understanding faculty and student beliefs about teamwork and communication skills," in Proc. 2012 ASEE American Society for Engineering Education Annual Conference \& Exposition, (San Antonio, Texas; 10-13 June 2012) 12 pp., 2012.

[13] Cary Moskovitz \& Michael Petit, "Insiders and outsiders: Redrawing the boundaries of the writing program," WPA: Writing Program Administration, vol.31, no.1-2, pp. 86103, Fall/Winter 2007

[14] Barbara M. Olds, Jon A. Leydens, Ronald L. Miller, "A flexible model for assessing WAC programs," Language and Learning Across the Disciplines, vol. 3, no. 2, pp. 123 129, July 1999.

[15] Marie C. Paretti, "Teaching communication in capstone design: The role of the instructor in situated learning," Journal of Engineering Education, vol. 97, no. 4, pp. 491503, October 2008.

[16] Marie Paretti, Lisa D. McNair, "Introduction to the special issue on communication in engineering curricula: Mapping the landscape," IEEE Transactions on Professional Communication, vol. 51, no. 3, pp. 228-241, September 2008 .

[17] Marie Paretti, Lisa McNair, Kelly Belanger, Diana George, "Reformist possibilities? Exploring writing program cross-campus partnerships," WPA: Writing Program Administration, vol.33, no.1-2, pp. 74-113, Fall/Winter 2009.

[18] Marie Paretti, Lisa McNair, Diana George, Kelly Belanger, \& Lisa Norris, "Outcomes assessment as a site of integration: ABET meets The Council of Writing Program Administrators," in Proc. 2007 ASEE American Society for Engineering Education Annual Conference \& Exposition, (Honolulu, Hawaii; 24-27 June 2007) 16 pp., 2007.
[19] Martha D. Patton, "Beyond WI: Building an integrated communication curriculum in one department of civil engineering," IEEE Transactions on Professional Communication, vol. 51, no. 3, pp. 313-327, September 2008 .

[20] Barbara Shwom, Penny Hirsch, John C. Anderson, Charles Yarnoff \& David Kelso, "Using multi disciplinary teams to teach communication to engineers, or 'Practicing what we preach," in Proc. 2000 ASEE American Society for Engineering Education Annual Conference \& Exposition, (St. Louis, Missouri; 18-21 June 2000) 8 pp., 2000.

[21] Natascha M. Trellinger, Brent K. Jesiek, Cary Troy, Josh Boyd, Rebecca R. Essig, "Engineering faculty on writing: What they think and what they want," in Proc. 2016 ASEE American Society for Engineering Education Annual Conference \& Exposition, (New Orleans, Louisiana; 26-28 June 2016) 16 pp., 2016.

[22] Kristin Walker, "Integrating writing instruction into engineering courses: A writing center model, Journal of Engineering Education, vol. 89, no. 3, pp. 369-375, July 2000

[23] Edward Wheeler, Robert L. McDonald, "Writing in engineering courses," Journal of Engineering Education, vol. 89, no. 4, pp. 481-486, October 2000.

[24] Dorothy A. Winsor, "Engineering writing/writing engineering, "College Composition and Communication, vol. 41, no. 1, pp. 58-70, 1990.

[25] Dorothy A. Winsor, "What counts as writing? An argument from engineers' practice," Journal of Advanced Composition, vol. 12, no. 2, pp. 337-347, Fall 1992.

[26] Dorothy A. Winsor, Writing Like an Engineer: A Rhetorical Education. Mahwah, NJ: Lawrence Erlbaum Associates, 1996. 